\title{
ARTICLE
}

\section{Unique distal size selectivity with a digold catalyst during alkyne homocoupling}

\author{
Antonio Leyva-Pérez ${ }^{1}$, Antonio Doménech-Carbó ${ }^{2} \&$ Avelino Corma $^{1}$
}

Metal-catalysed chemical reactions are often controlled by steric hindrance around the metal atom and it is rare that substituents far away of the reaction site could be differentiated during reaction, particularly if they are simple alkyl groups. Here we show that a gold catalyst is able to discriminate between linear carbon alkynes with 10 or 12 atoms in the chain during the oxidative homocoupling of alkynes: the former is fully reactive and the latter is practically unreactive. We present experimental evidences, which support that the distal size selectivity occurs by the impossibility of transmetallating two long alkyl chains in an A-framed, mixedvalence digold (I, III) acetylide complex. We also show that the reductive elimination of two alkyne molecules from a single $\mathrm{Au}(\mathrm{III})$ atom occurs extremely fast, in $<1 \mathrm{~min}$ at $-78^{\circ} \mathrm{C}$ (turnover frequency $>0.016 \mathrm{~s}^{-1}$ ).

\footnotetext{
${ }^{1}$ Instituto de Tecnología Química, Universidad Politécnica de Valencia-Consejo Superior de Investigaciones Científicas, Avda. de los Naranjos s/n, 46022 Valencia, Spain. ${ }^{2}$ Departament de Química Analítica, Universitat de Valencia, Dr Moliner, 50, 46100 Burjassot, Valencia, Spain. Correspondence and requests for materials should be addressed to A.L.-P. (email: anleyva@itq.upv.es) or to A.C. (email: acorma@itq.upv.es).
} 
$\mathrm{O}$ rganic synthesis takes advantage of the predictable outcome of reactions where bulky groups are involved. Metal-catalysed carbon-carbon bond-forming reactions are not an exception since they are generally controlled by the steric hindrance around the catalytic site, which is given by the bulkiness of the ligands or the reactants, rather than for substituents far away from the reactive site. It is rare that substituents at more than six atoms distance from the reactive site can be sterically differentiated during catalysis ${ }^{1,2}$. Here we show a gold catalyst that is able to discriminate between linear chain alkynes only differing in one ethylene group at an eight-carbon distance of the catalytic site. This level of discrimination is extraordinary and difficult to achieve even for rigid microporous solid frameworks ${ }^{3-5}$.

Gold catalysis has been intensively studied during the last decade and, in particular, the use of the redox pair $\mathrm{Au}(\mathrm{I}) / \mathrm{Au}(\mathrm{III})$ has arisen much interest among chemists as a catalyst for new carbon-carbon and carbon-heteroatom bond-forming reactions ${ }^{6-10}$. Despite the increasing number of new transformations reported, particularly with alkynes ${ }^{11,12}$, fundamental studies covering the elemental steps of the goldcatalysed redox cycle remain scarce ${ }^{13,14}$.

Here we dissect the fundamental steps during the oxidative coupling of alkynes catalysed by $\mathrm{Au}(\mathrm{I}) / \mathrm{Au}(\mathrm{III})$ to find a reasonable explanation to the distal size selectivity observed.

\section{Results}

Distal size selectivity of alkynes with gold catalysts. Fig. 1 shows the results for the homocoupling of 1-decyne 1a and 1 -dodecyne $\mathbf{1 b}$ under gold-catalysed conditions. We found that 1-decyne 1a $\left(\mathrm{C}_{10}\right)$ reacts smoothly under the gold-catalysed conditions, while 1 -dodecyne $\mathbf{1 b}$ is nearly unreactive for homocoupling $(<5 \%$ yield after $24 \mathrm{~h})$. Kinetic measurements by gas chromatography-mass spectrometry (GC-MS, see Supplementary Fig. 1) show that the initial rate of 1-decyne 1a is 3.5 times higher than 1-dodecyne $\mathbf{1 b}$, and that while 1a smoothly converts over the time to the homocoupling product 2a 1-dodecyne $\mathbf{1 b}$ rapidly stops converting to the homocoupled product $\mathbf{2 b}$. Notice that a minor non-catalysed polymerization of the alkyne occurs together with the homocoupling reaction.

Other linear terminal alkynes shorter than 1-decyne 1a $\left(\mathrm{C}_{6}-\mathrm{C}_{9}\right)$ react at a similar rate than $\mathbf{1 a}$ under gold-catalysed conditions, with final product yields between $60-70 \%$, while 1-undecyne $\left(\mathrm{C}_{11}\right)$ gives a low yield of homocoupling product $(19 \%)$ and a longer linear terminal alkyne $\left(C_{14}\right)$ is unreactive towards homocoupling. The use of freshly-prepared or just-open commercial bottles of $\mathrm{Au}$ catalyst and selectfluor assures reproducible results, otherwise lower yields can be obtained although with still a similar distal size selectivity. This change based on the chain size is remarkable, when moving from 1-decyne 1a (65-80\%), then to 1-undecyne (19\%) and finally to 1 -dodecyne $\mathbf{1 b}$ and longer linear alkynes $(<5 \%)$. It must be highlighted that this distal size selectivity seems to be quite unique with gold, since when the homocoupling of alkynes was carried out under typical copper-mediated (Glaser coupling, that is, the most used protocol for the homocoupling of alkynes in organic synthesis) ${ }^{15,16}$ or copper-catalysed (Glaser-Hay coupling, with $\mathrm{O}_{2}$ as the final oxidant) conditions the reaction rate and final yields of 1-decyne $\mathbf{2 a}$ and 1 -dodecyne $\mathbf{2 b}$ are very similar for both alkynes (see Fig. 1). These results suggest a profound difference in the mechanism of homocoupling of linear alkynes with gold or copper catalysts.

The nearly atomically precise selection of long linear alkynes by gold during the oxidative homocoupling of alkynes is perhaps more striking when we consider alkynes containing bulky substituents at the contiguous positions of the triple bond. For instance, tert-butylacetylene 1c reacts smoothly (91\% yield of 2 c) while cyclohexylacetylene $\mathbf{1 d}$ gives only a moderate yield of homocoupling product $\mathbf{2 d}$ (37\% yield). These results clearly contrast with those obtained for copper: while tert-butylacetylene $\mathbf{1 c}$ is poorly reactive in the Glaser and Hay couplings (11 and 34\% yield after $24 \mathrm{~h}$ ), cyclohexylacetylene $1 \mathrm{~d}$ shows a higher reactivity ( $46 \%$ yield after 4 days for the Glaser coupling and 53\% yield after $24 \mathrm{~h}$ for the Hay coupling) closer to that of long linear alkynes 1a-b. Overall, the results in Fig. 1 clearly show that the goldcatalysed oxidative homocoupling of alkynes occurs with size selectivity along the whole substrate rather than with the classical size selectivity around the reactive site of the substrate, the latter operating in the copper-catalysed reactions.

Study of the origin of the distal size selectivity with gold catalysts. The elemental steps of the homocoupling of alkynes on gold catalysts (supposing a mixed-valence gold complex) are shown in Fig. 2 and include oxidation of gold(I) to gold (III), formation of the digold complex (approach), transmetallation of the alkyne and reductive elimination 17,18 .

To determine if the first step, that is, the oxidation by selectfluor of the in situ formed gold(I)-acetylide ${ }^{17}$, is responsible for the distal size selectivity observed, the gold(I) acetylides of 1-decyne 1a (3a) and 1-dodecyne $\mathbf{1 b}(\mathbf{3} \mathbf{b})$ were prepared and a stoichiometric amount of oxidant was added to each of them under the reaction conditions given in Fig. 3.

The results show that selectfluor is consumed within $45 \mathrm{~min}$ with an initial rate of $250 \mathrm{~h}^{-1}$ for acetylide $3 \mathrm{a}$ and $220 \mathrm{~h}^{-1}$ for 3b (measured from the initial slope of the curve and within the timing limitations of the ${ }^{1} \mathrm{H}$ NMR technique). The reaction rate is

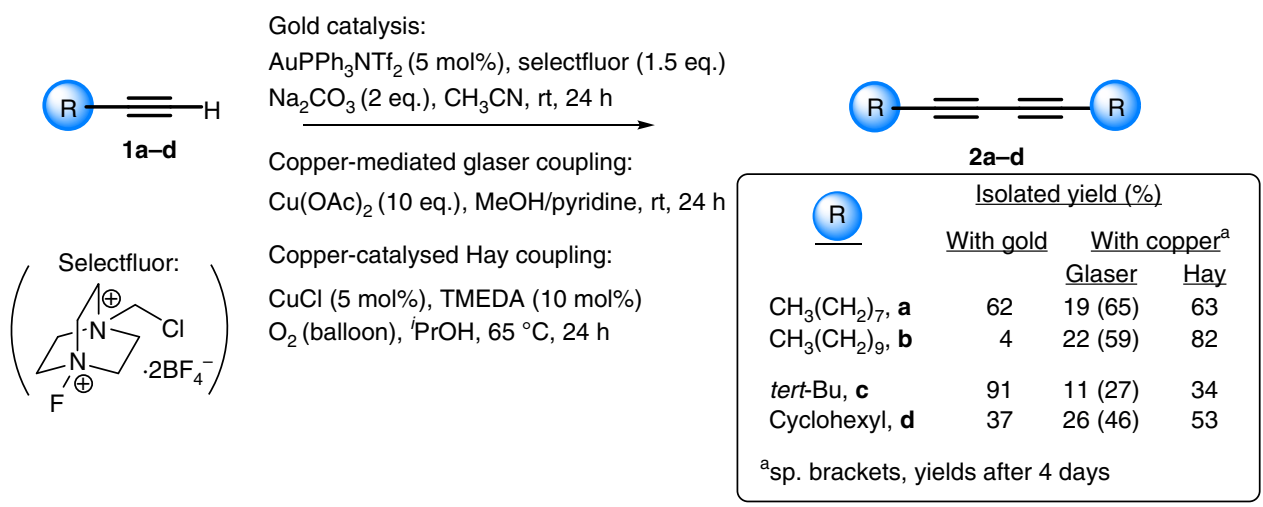

Figure 1 | Gold or copper-catalysed oxidative homocoupling of terminal alkynes. Notice the different reactivity of alkynes 1a-d under the gold-catalysed conditions reported here and typical copper-catalysed conditions (Glaser or Hay conditions). Isolated yields are the average of two runs. 


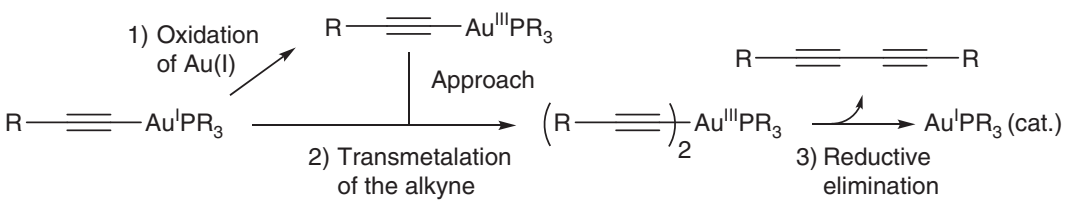

Figure 2 | Proposed reaction steps for the homocoupling of alkynes on gold catalysts. The reaction pathway includes oxidation of gold(I) to gold (III), formation of the digold complex (approach), transmetallation of the alkyne and reductive elimination ${ }^{17}$.
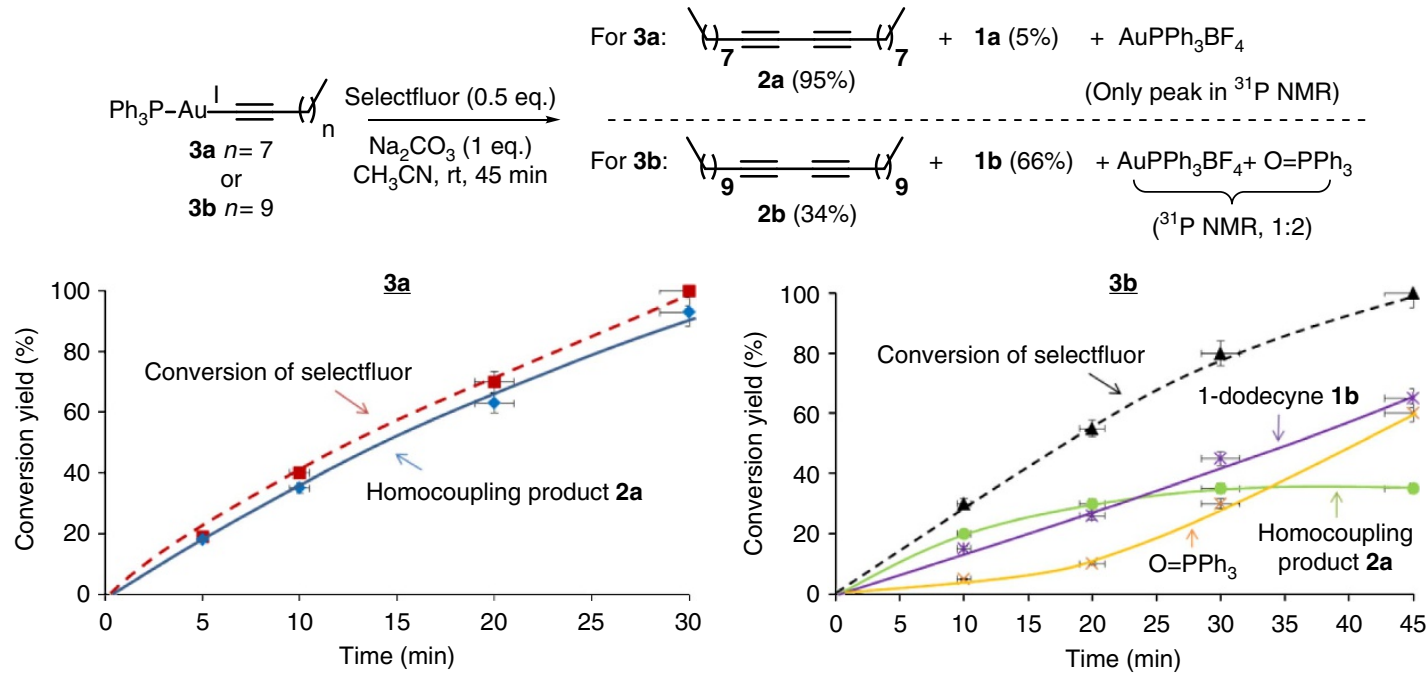

Figure 3 | Oxidation of gold(I) acetylides by selectfluor. Conversion and yields are calculated on the basis of ${ }^{1} \mathrm{H}$ and ${ }^{19} \mathrm{~F}$ NMR spectroscopy for selectfluor, ${ }^{1} \mathrm{H}$ NMR spectroscopy and GC-MS (after extraction of the reaction mixture with $n$-hexane and addition of dodecane as an external standard) for alkynes and ${ }^{31} \mathrm{P}$ NMR spectroscopy for phosphines. Error bars represent an uncertainty of $5 \%$ in the value.

expressed in $\mathrm{h}^{-1}$ and increases with the concentration of selectfluor (Supplementary Fig. 2) ${ }^{17}$. While the consumption of selectfluor is similar for the two acetylides $\mathbf{3} \mathbf{a}-\mathbf{b}$, the appearance of the homocoupling product is not. For $3 \mathbf{a}\left(\mathrm{C}_{10}\right)$, a new triplet at $\sim 2.1$ p.p.m. corresponding to the homocoupling product 2 a appears in the ${ }^{1} \mathrm{H}$ NMR spectra, and this peak increases as selectfluor converts. In contrast, $\mathbf{3 b}\left(\mathrm{C}_{12}\right)$ gives two new signals in the ${ }^{1} \mathrm{H}$ NMR spectra at $\sim 2.3-2.1$ p.p.m., and those signals correspond to the homocoupling product $\mathbf{2 b}$ and 1 -dodecyne $\mathbf{1 b}$. Extraction of the reaction mixture with $n$-hexane and analysis by GC-MS and also by ${ }^{1} \mathrm{H}$ and ${ }^{13} \mathrm{C}$ NMR spectroscopy confirms that the homocoupling product $\mathbf{2 a}$ is the only alkyne product after oxidation of the acetylide of $\mathbf{3 a}$, and that the homocoupling product $\mathbf{2 b}$ and free 1-dodecyne $\mathbf{1 b}$ in a 1:2 molar ratio are the alkyne products from the acetylide of $\mathbf{3 b}$. The appearance of free alkyne $\mathbf{1 b}$ from $\mathbf{3 b}$ prompted us to check carefully the spectra of $\mathbf{3 a}$ during oxidation, and small amounts $(<5 \%)$ of free 1-decyne 1a were detected in solution by GC-MS. These results show that the free alkynes $\mathbf{1 a}$ or $\mathbf{1 b}$ are somehow formed during the oxidation of the $\mathrm{Au}(\mathrm{I})$ acetylide complexes $\mathbf{3 a}-\mathbf{b}$, respectively.

To check if the free alkyne is able or not to enter back the catalytic cycle, an equimolecular amount of 1-dodecyne $\mathbf{1 b}$ was added to the $\mathrm{C}_{10}$ acetylide $\mathbf{3} \mathbf{a}$ and then we proceed to oxidize with selectfluor. The results (Supplementary Fig. 3) show that the heterocoupling product $\mathrm{C}_{10}-\mathrm{C}_{12} \mathbf{4 a}$ was formed together with the homocoupling product $\mathrm{C}_{10}-\mathrm{C}_{10}$ 2a. Complementary 1-decyne 1a was added during the oxidation of the $C_{12}$ acetylide $\mathbf{3} \mathbf{b}$, and we found again that the heterocoupling product $\mathrm{C}_{10}-\mathrm{C}_{12}$ 4a was formed together with the corresponding homocoupling product $\mathrm{C}_{12}-\mathrm{C}_{12} \mathbf{2 b}$. These results confirm the scrambling of alkynes during reaction. Notice that the homocoupling product of the free alkyne added externally is not obtained in any case, which is in accordance with blank experiments that show that alkyne scrambling between the gold(I) acetylide and a second free alkyne does not occur without any oxidant in the reaction medium. When the two gold(I) acetylides $\mathbf{3 a}$ and $\mathbf{3 b}$ are combined in a single flask and selectfluor is added, the heterocoupling product $\mathbf{4 a}$ is formed in $37 \%$ yield, the $\mathrm{C}_{10}-\mathrm{C}_{10}$ homocoupling product $\mathbf{2 a}$ is formed in $58 \%$ yield, the $\mathrm{C}_{12}-\mathrm{C}_{12} \mathbf{2 b}$ is formed in only $5 \%$ yield and the free alkyne $\mathbf{1 b}(50 \%)$ persists in solution. These results support that free alkyne is released after oxidation by selectfluor of the acetylide $\mathrm{Au}(\mathrm{I})$ complex, that the amount of free alkyne remaining in solution during the coupling is much higher for the $\mathrm{C}_{12}$ than for the $\mathrm{C}_{10}$ gold(I) acetylide, and that the released alkyne re-enters into the catalytic cycle. If anhydrous acetonitrile with a $0.5 \%(\mathrm{v}: \mathrm{v})$ of $\mathrm{D}_{2} \mathrm{O}$ is used as a reaction solvent (instead of non-dried acetonitrile) for the oxidation of $3 \mathbf{b}$, much of the alkyne released $(\sim 80 \%)$ is $d^{1}-1$ dodecyne $\mathbf{1 b}-\boldsymbol{d}^{\mathbf{1}}$, which suggests that the released alkyne takes the proton from the solvent.

${ }^{31} \mathrm{P}$ NMR spectroscopy also shows significant differences during the oxidation by selectfluor of $\mathbf{3} \mathbf{a}$ and $\mathbf{3} \mathbf{b}$. For the former $\left(\mathrm{C}_{10}\right)$, the original peak of phosphine $3 \mathrm{a}$ at $\sim 42$ p.p.m. disappears as the oxidation converts and the generation of a single new peak at 232 p.p.m. corresponding to $\mathrm{PPh}_{3} \mathrm{AuBF}_{4}$ is observed. In contrast, $3 \mathbf{b}\left(\mathrm{C}_{10}\right)$ shows that the original peak ( $\sim 42$ p.p.m.) is transformed into $\mathrm{PPh}_{3} \mathrm{AuBF}_{4}$ (32 p.p.m.) and also into free $\mathrm{O}=\mathrm{PPh}_{3}$ (28 p.p.m.) in a 1:2 molar ratio. Despite homocoupling of the alkyne being incomplete, ${ }^{1} \mathrm{H}$ and ${ }^{19} \mathrm{~F}$ spectroscopy clearly show the total consumption of selectfluor. Kinetic measurements (see Fig. 3 above) show that as soon as the formation of the homocoupling $\mathrm{C}_{12}$ product $\mathbf{2} \mathbf{b}$ stops during the oxidation of $\mathbf{3 b}$ with selectfluor, the formation of free $\mathrm{O}=\mathrm{PPh}_{3}$ increases. A new downshifted peak attributable to a phosphine oxide-gold complex was found during reaction by ${ }^{31} \mathrm{P}$ NMR spectroscopy 
(Supplementary Fig. 3). No additional ${ }^{31} \mathrm{P}$ peaks were found during oxidation, which suggests that phosphine ligands are not detached during reaction, at least at a measurable rate, and that transmetallation (if occurs) and reductive elimination are much faster processes than gold(I) oxidation since no phosphine intermediates are detected. These results indicate that the oxidation of the phosphine follows the oxidation of gold(I) to gold(III), and when the former occurs the active acetylide gold species decompose to $\mathrm{O}=\mathrm{PPh}_{3}$, free terminal alkyne and gold $^{19,20}$.

In any case, the results showed above are consistent with the oxidation by selectfluor of the gold(I) acetylide complex independently of the size of the alkyne, with release of homocoupling product and also of free alkyne into the solution. This free alkyne is able to re-enter into the catalytic cycle provided the gold active species is still active. In the case of the
$\mathrm{C}_{10}$ acetylide $\mathbf{3 a}$, the amount of free alkyne $\mathbf{1 a}$ detected in the solution is very low and the main alkyne product is the homocoupling product $\mathbf{2 a}$. In contrast, the $\mathrm{C}_{12}$ acetylide $\mathbf{3 b}$ leaves significant amounts of 1-docecyne $\mathbf{1 b}$ in solution which, at the end, does not form back productive acetylide gold complex for further homocoupling, at least at a rate that could compete with the destruction of the gold catalyst by oxidation of the metal ligand $\mathrm{PPh}_{3}$ to $\mathrm{O}=\mathrm{PPh}_{3}$.

The results in Figs 1 and 3 suggest that the distal size selectivity observed for gold occurs after oxidation, when both species $\mathrm{Au}(\mathrm{I})$ and $\mathrm{Au}(\mathrm{III})$ are already present in the reaction medium. Previous mechanistic studies unveiled that the gold-catalysed oxidative homocoupling of alkynes in solution proceeds through a bimetallic $\mathrm{Au}(\mathrm{I}) / \mathrm{Au}(\mathrm{III})$ acetylide transition state ${ }^{17}$, and density functional theory calculations confirm the feasibility of a digold intermediate species (Supplementary Fig. 4). The digold

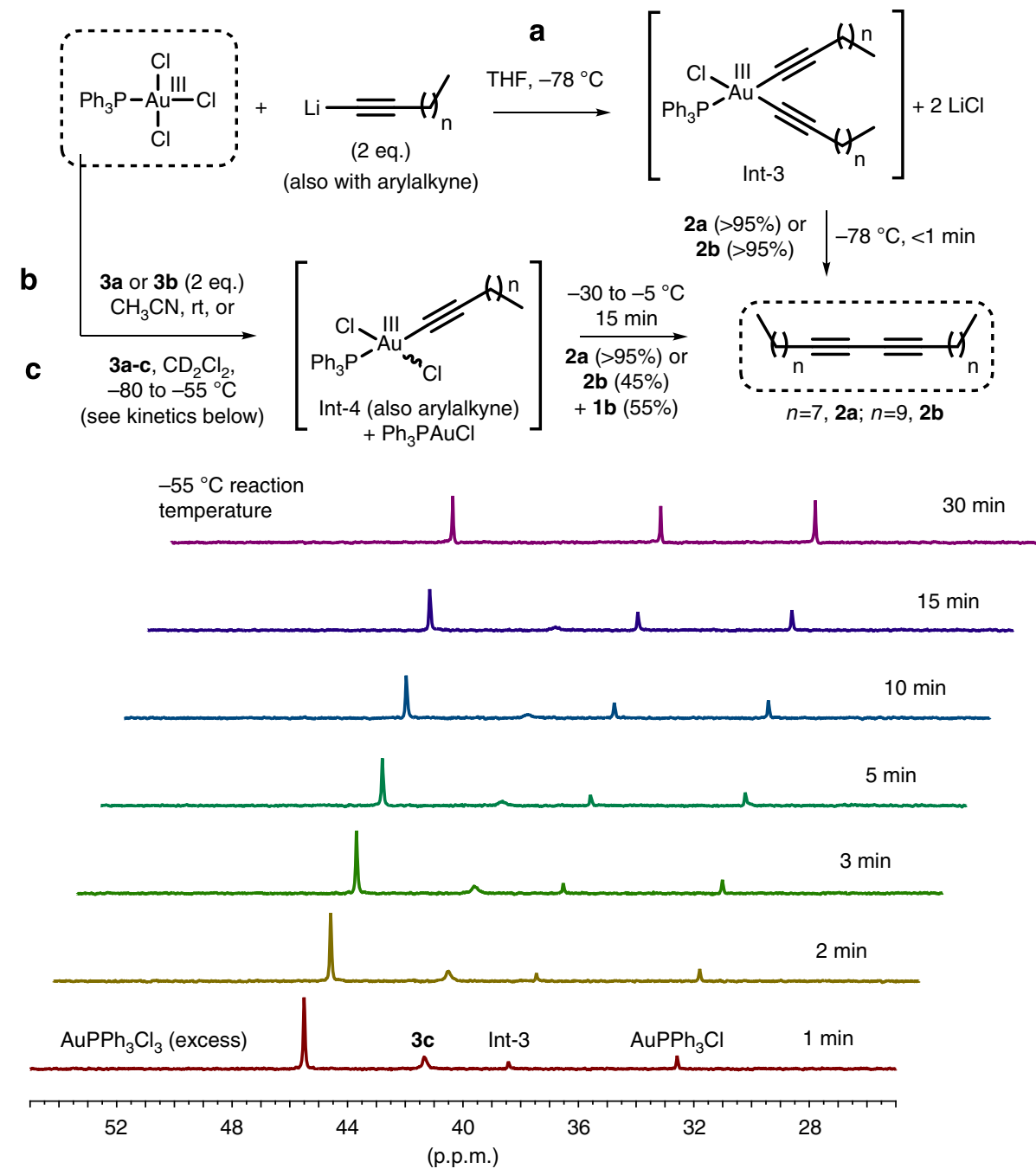

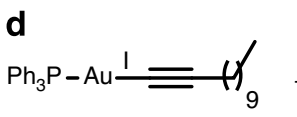

3b

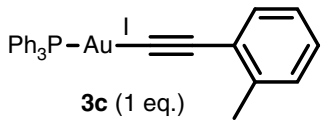

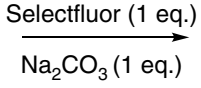

$\mathrm{CH}_{3} \mathrm{CN}$, rt, $30 \mathrm{~min}$

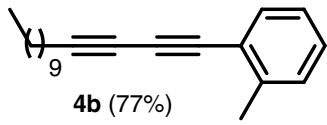

Figure 4 | Studies on the reductive elimination step. The top schemes (a-c) show the reductive elimination or transmetallation between gold and/or lithium acetylides in stoichiometric amounts. GC yields refer after extraction of the reaction mixture with $n$-hexane and addition of dodecane as an external standard. The kinetics at low-temperature of the transmetallation of tolylacetylene from $\mathbf{3} \mathbf{c}$ to an excess ( 3 equiv.) of $\mathrm{AuPPh}_{3} \mathrm{Cl}_{3}$, followed by ${ }^{31} \mathrm{P} \mathrm{NMR}$, is also included. Spectra were recorded every $30 \mathrm{~s}$ after $1 \mathrm{scan}(2.5 \mathrm{~s})$, and a total of 60 measurements were taken. The in situ oxidation and transmetallation of gold(I) alkyl and aryl acetylides is shown at the bottom (d). 
intermediate sets the $\mathrm{Au}(\mathrm{I}) / \mathrm{Au}(\mathrm{III})$ cations in position and, as a consequence, the alkynes are oriented in a cisoid conformation. If one compares this reaction intermediate for gold with that widely accepted for copper ${ }^{21}$ consisting in a tetrahedrically coordinated dimeric $\mathrm{Cu}(\mathrm{II})$ acetylide species with the alkynes oriented in opposite directions, one can attempt to explain the different behaviour of gold and copper on the basis of the different geometries.

To assess if the spatial approaching of the two gold atoms has any influence on the reaction outcome, three different diphenylphosphine-bridged digold(I) complexes 5a-c with one (methylene), two (ethylene) and three (propylene) methylene units in the tether were prepared (Supplementary Fig. 5 and Supplementary Discussion) ${ }^{22,23}$. X-ray Diffraction together with cyclic voltammetry studies showed that while $\mathbf{5 a}$ presents aurophilic bonding between two gold atoms ${ }^{14}, 5 \mathrm{c}$ has no aurophilic bonds at all ${ }^{14}$ and $\mathbf{5 b}$ has an intermediate behaviour, depending on the counteranion ${ }^{24,25}$. The results indicate that aurophilic bonding has a positive influence on the reaction rate but none on the distal size selectivity. Since previous kinetic studies have demonstrated that the rate-determining step of the gold-catalysed homocoupling of alkynes in solution is the oxidation of $\operatorname{gold}(\mathrm{I})^{17}$, it is not surprising that aurophilic bonding improves the reaction rate by neighbouring gold atomassisted oxidation of gold(I ${ }^{26,27}$. To test if aurophilic bonding has also any influence in the distal size selectivity, we prepared the digold acetylide complexes $\mathbf{6 a}\left[\mathrm{Au}_{2} \mathrm{dppe}\left(\mathrm{C}_{10}\right)_{2}\right]$ and $\mathbf{6 b}$ $\left[\mathrm{Au}_{2} \mathrm{dppe}\left(\mathrm{C}_{12}\right)_{2}\right]$, and the results after oxidation with selectfluor were compared with those obtained before for the corresponding monogold acetylides $\mathbf{3 a}-\mathbf{b}$. The results were nearly identical, with the same amounts of homocoupling products $\mathbf{2 a}(>95 \%)$ or $\mathbf{2 b}$ (45\%) obtained, and free alkyne 1-dodecyne $\mathbf{1 b}(\sim 50 \%)$ released into solution for the case of the dodecynyl acetylide $\mathbf{6 b}$. Cyclic voltammetry (Supplementary Figs 6 and 7 and Supplementary Discussion) confirmed that, in all the complexes tested, oxidation of $\mathrm{Au}(\mathrm{I})$ to $\mathrm{Au}(\mathrm{III})$ occurs without detecting any $\mathrm{Au}(\mathrm{II})$ species $9,16,23,28$. These results validate the mixed-valence digold intermediate Int-1 and clearly show that aurophilic bonding improves the reaction rate but that it is not involved in the distal size selectivity.

The reductive elimination from $\mathrm{Au}(\mathrm{III})$ complexes to form new $\mathrm{C}_{\mathrm{sp}^{3}}-\mathrm{X}$ and $\mathrm{C}_{\mathrm{sp}^{2}}-\mathrm{X}$ bonds $\left(\mathrm{X}=\right.$ heteroatom, $\left.\mathrm{C}_{\mathrm{sp}^{3}}, \mathrm{C}_{\mathrm{sp}^{2}}, \ldots\right)$ is a well-known process ${ }^{13,29-32}$ that has been recently reported to occur very rapidly (even at $\left.-52{ }^{\circ} \mathrm{C}\right)^{33}$, faster than in palladium (II). $\mathrm{Au}$ (III) intermediates have been isolated and characterized $^{34-36}$. Despite the great body of work reported in the literature for alkynes and gold, the reductive elimination of $\mathrm{C}_{\mathrm{sp}}$ bonds from $\mathrm{Au}(\mathrm{III})$ complexes has not been reported yet as far as we know ${ }^{8}$, and very few examples of stable $\mathrm{Au}(\mathrm{III})$-diacetylide complexes appear in the literature ${ }^{37,38}$. This lack of precedents for $\mathrm{Au}(\mathrm{III})$-diacetylides might indicate that the reactivity of the alkynes once $\sigma$-bound to $\mathrm{Au}(\mathrm{III})$ is very high, including a potential reductive elimination. It has been proposed that the reductive elimination from a tetracoordinated planar $\mathrm{Au}(\mathrm{III})$ complex is favoured respect to other metals ${ }^{33}$ since it leaves behind a two-coordinated $\mathrm{Au}(\mathrm{I})$ complex stabilized by relativistic effects $^{39-41}$. To study the reductive elimination of alkynes from $\mathrm{Au}(\mathrm{III})$ and also if the distal size selectivity occurs at this stage, the $\mathrm{Au}(\mathrm{III})$ complex $\mathrm{PPh}_{3} \mathrm{AuCl}_{3}$ was prepared ${ }^{42}$ and the corresponding $\mathrm{Au}$ (III) acetylide complex of 1-dodecyne $\mathbf{1 b}$ was forced to be formed ${ }^{43}$. To do that, $n$-BuLi was added to 1-dodecyne $\mathbf{1 b}$ in tetrahydrofurane (THF)- $d^{8}$ at $-78^{\circ} \mathrm{C}$ and the resulting solution was added to $\mathrm{PPh}_{3} \mathrm{AuCl}_{3}$ suspended (not soluble) in THF- $d^{8}$ at room temperature (2 equiv. of lithium acetylide with respect to gold). The result is shown in Fig. 4a. The bright-yellow complex $\mathrm{PPh}_{3} \mathrm{AuCl}_{3}$ became immediately
$(<1 \mathrm{~min})$ colourless and soluble. ${ }^{31} \mathrm{P}$ NMR spectroscopy of the solution just after addition of the acetylide solution shows the complete disappearance of the original signal of $\mathrm{PPh}_{3} \mathrm{AuCl}_{3}$ (42 p.p.m.) and the appearance of a new single peak at 33 p.p.m. that could correspond to $\mathrm{AuPPh}_{3} \mathrm{Cl}$. Addition of $n$-hexane to the THF solution precipitates a white solid that by isolation and characterization with ${ }^{1} \mathrm{H}$ and ${ }^{31} \mathrm{P}$ NMR spectroscopy was confirmed to be $\mathrm{AuPPh}_{3} \mathrm{Cl}$, the corresponding phosphine peak being observed during reaction. Analysis by GC-MS of the $n$-hexane supernatant shows that the homocoupling $\mathrm{C}_{12}$ product $\mathbf{2 b}$ is the only alkyne product of the reaction, no traces of free 1-dodecyne $\mathbf{1 b}$ being present. A similar result is obtained when $\mathrm{PPh}_{3} \mathrm{AuCl}_{3}$ is treated with the lithium acetylide of 1-decyne $\mathbf{1 a}$ since $\mathrm{AuPPh}_{3} \mathrm{Cl}$ and the $\mathrm{C}_{10}$ homocoupling product $2 \mathbf{a}$ are the only products of the reaction. These results indicate that the reductive elimination of two acetylide fragments from a single $\mathrm{Au}$ (III) atom is very fast, in accordance with recent precedents in the literature that reports the efficient formation of $\mathrm{C}_{\mathrm{sp}} 2-\mathrm{C}_{\mathrm{sp}} 2$ bond with $\mathrm{Au}(\mathrm{III})$ via reductive elimination at $-52^{\circ} \mathrm{C}$ reaction temperature $^{30}$. Thus, we must conclude that the distal size selectivity does not occur during the final reductive elimination but occurs in an intermediate step between oxidation and reductive elimination, since reductive elimination of the two alkyne molecules from $\mathrm{Au}(\mathrm{III})$ is extremely fast and does not give any distal size selectivity.

Gold is the most electronegative metal of the periodic table and, consequently, transmetallation of carbon ligands from $\mathrm{Au}(\mathrm{I})-\mathrm{C}$ and $\mathrm{Au}(\mathrm{III})-\mathrm{C}$ bonds to other metals is favoured and well-reported in the literature ${ }^{44-46}$. However, transmetallation from $\mathrm{Au}(\mathrm{I})$ to $\mathrm{Au}(\mathrm{III})$ is scarcely reported ${ }^{29}$ although the migration of a carbon ligand from the more electronegative $\mathrm{Au}(\mathrm{I})$ to the more electropositive $\mathrm{Au}(\mathrm{III})$ cation should be favoured. Figure $4 \mathrm{~b}$ shows the results obtained when the $\mathrm{C}_{10}$ $\mathrm{Au}(\mathrm{I})$ acetylide $\mathbf{3 a}$ was mixed with the $\mathrm{Au}(\mathrm{III})$ complex $\mathrm{PPh}_{3} \mathrm{AuCl}_{3}$ in acetonitrile. In this case, the homocoupling product $2 \mathbf{a}$ is formed as only alkyne product in $<5 \mathrm{~min}$ at room temperature. This result suggests that the transmetallation of the $\mathrm{C}_{10}$ acetylide fragment of $\mathrm{Au}(\mathrm{I})$ complex $\mathbf{3 a}$ to the $\mathrm{Au}(\mathrm{III})$ cation readily occurs. When the $\mathrm{C}_{12} \mathrm{Au}(\mathrm{I})$ acetylide $\mathbf{3 b}$ was used, the homocoupling product $\mathbf{2 b}$ was obtained together with free 1dodecyne $\mathbf{1 b}$, as described before. To better study this step, we followed the reaction of $\mathrm{PPh}_{3} \mathrm{AuCl}_{3}$ with $\mathbf{3 a}\left(\mathrm{C}_{10}\right)$ or $\mathbf{3 b}\left(\mathrm{C}_{12}\right)$, and also with $\mathrm{Au}(\mathrm{I})$ arylacetylide $3 \mathrm{c}\left(\mathrm{PPh}_{3} \mathrm{Au}\right.$-ortho-tolylacetylene), by means of low-temperature ${ }^{31} \mathrm{P}$ NMR spectroscopy (Fig. $4 \mathrm{c}$ and kinetics). For doing that, the NMR tube containing a solution of $\mathrm{PPh}_{3} \mathrm{AuCl}_{3}$ in $\mathrm{CD}_{2} \mathrm{Cl}_{2}$ was placed in liquid nitrogen $\left(-196^{\circ} \mathrm{C}\right)$ and then a solution of the corresponding $\mathrm{Au}(\mathrm{I})$ acetylide $\mathbf{3 a}-\mathbf{c}$ in $\mathrm{CD}_{2} \mathrm{Cl}_{2}$, cooled at $-78{ }^{\circ} \mathrm{C}$ (acetone-dry ice), was slowly added into the NMR tube. After that, the tube was rapidly transferred to the NMR equipment at $-80^{\circ} \mathrm{C}$, and measurements were started after shimming. It was found that $\mathbf{3 a}$ or $\mathbf{3 b}$ react with $\mathrm{PPh}_{3} \mathrm{AuCl}_{3}$ in $<5 \mathrm{~min}$ at $-80^{\circ} \mathrm{C}$ to give 0.5 equiv. of $\mathrm{PPh}_{3} \mathrm{AuCl}$ and 0.5 equiv. of an unknown phosphine product at 38 p.p.m. and that this intermediate (Int-4) is stable at least up to $-30^{\circ} \mathrm{C}$. No differences between $\mathbf{3 a}\left(\mathrm{C}_{10}\right)$ and $\mathbf{3 b}\left(\mathrm{C}_{12}\right)$ were found here. When the NMR tube was left to warm, the only peak found by ${ }^{31} \mathrm{P}$ NMR was that corresponding to $\mathrm{PPh}_{3} \mathrm{AuCl} .{ }^{1} \mathrm{H}$ and ${ }^{13} \mathrm{C} \quad \mathrm{NMR}$ confirmed the formation of the homocoupling product $2 \mathrm{a}$ from $\mathbf{3} \mathbf{a}$ and the mixture of $\mathbf{1 b}$ and $\mathbf{2} \mathbf{b}$ from $\mathbf{3 b}$.

The reaction of $\mathrm{PPh}_{3} \mathrm{AuCl}_{3}$ with $3 \mathrm{c}$ proceeds slower and a more accurate kinetics could be carried out at $-55^{\circ} \mathrm{C}$. Again, $\mathrm{PPh}_{3} \mathrm{AuCl}$ and the unknown peak at 38 p.p.m. were the only products formed in equimolecular amounts. In situ ${ }^{1} \mathrm{H}$ measurements of the reaction mixture at $-55^{\circ} \mathrm{C}$ showed a new peak at 2.40 p.p.m. downshifted -0.05 p.p.m. from the original methyl group of the $\mathrm{Au}(\mathrm{I})$ tolylacetylide $3 \mathrm{c}$ (2.45) and also downshifted 
( -0.11 p.p.m.) from the homocoupled product (2.51). It is perhaps more informative the result obtained by in situ ${ }^{13} \mathrm{C} N \mathrm{NR}$ measurement at $-55^{\circ} \mathrm{C}$. It was found that new peaks corresponding to the arene ring of the alkyne appear and that they present the typical $J_{C-P}$ of the phosphine Au-acetylide complexes and, consistently, that the methyl peak is also shifted with respect to the starting material. The ${ }^{13} \mathrm{C}$ NMR spectrum strongly suggests that the unknown species at 38 p.p.m. is a new phosphine Au-acetylide that, according to the formation of 1 equiv. of $\mathrm{AuPPh}_{3} \mathrm{Cl}$ per molecule of $3 \mathrm{c}$ consumed, it might correspond to $\mathrm{PPh}_{3} \mathrm{Au}(\mathrm{III})$-tolylacetylene. A similar result is found when lithium tolylacetylide is used. The downshift of the methyl group in ${ }^{1} \mathrm{H}$ NMR points also in that direction. To further assess if Int-4 is the result of one alkyne transmetallation from $3 \mathrm{c}$ to $\mathrm{PPh}_{3} \mathrm{AuCl}_{3}$, the reaction was carried out with an excess ( 3 equiv.) of the latter to maximize monotransmetallation. Kinetics of the reaction in Fig. 4 gives an initial rate of $0.28 \mathrm{~s}^{-1}$. In situ ${ }^{1} \mathrm{H}$ and ${ }^{13} \mathrm{C}$ measurements of the reaction mixture at $-55^{\circ} \mathrm{C}$ after consumption of the $\mathrm{Au}(\mathrm{I})$ acetylide $3 \mathrm{c}$ gave neat spectra with the same phosphine intermediate found above. As for $\mathbf{3 a}$ and $\mathbf{3 b}$, this intermediate is stable up to $-5^{\circ} \mathrm{C}$ and only at this temperature it starts to further convert into $\mathrm{PPh}_{3} \mathrm{AuCl}$. The kinetic results together with the stoichiometry of the reaction suggest that the gold(I)-acetylides $\mathbf{3 a}-\mathbf{c}$ transfer the first alkyne group to the $\mathrm{Au}(\mathrm{III})$ atom of $\mathrm{PPh}_{3} \mathrm{AuCl}_{3}$ at low temperature $\left(-80^{\circ} \mathrm{C}\right.$ for alkyl, $-55^{\circ} \mathrm{C}$ for aryl) to give the intermediate Int-4 $\mathrm{PPh}_{3} \mathrm{Au}(\mathrm{III})$-alkyne and that the second alkyne transfers at much higher temperature $\left(-30\right.$ to $\left.-5^{\circ} \mathrm{C}\right)$ to give Int-3. As soon as Int-3 is formed, reductive elimination occurs and the homocoupling product is released. This means that the transmetallation of the second alkyne is much slower than the transmetallation of the first alkyne, since the former occurs at much higher temperature, and that the reductive elimination is in turn much faster than the second alkyne transmetallation, which correlates well with the results observed with lithium acetylides. In short, these results show that Int-4 is an intermediate of the reaction and that it could very well occur that the mixture of $\mathrm{Au}(\mathrm{I})$ acetylide and Int- 4 is responsible for the distal size selectivity observed.

To mimic better the gold-catalysed system when having separated $\mathrm{Au}(\mathrm{III})$ and $\mathrm{Au}(\mathrm{I})$ acetylides, and to avoid the use of $\mathrm{PPh}_{3} \mathrm{AuCl}_{3}$, we made use of the different rates of oxidation with selectfluor of alkyl and aryl acetylides. It was shown above that the oxidation of the alkyl acetylide complexes 3a-b (monogold) and $\mathbf{6 a - b}$ (digold) by selectfluor proceeds in $\sim 30 \mathrm{~min}$, and we have previously shown that the same oxidation for $\mathrm{PPh}_{3} \mathrm{Au}$ ortho-tolylacetylene $3 \mathrm{c}$ takes place in $\sim 4 \mathrm{~h}^{17}$. Thus, in principle, the addition of selectfluor to a mixture of an $\mathrm{Au}(\mathrm{I})$ alkyl acetylide and an $\mathrm{Au}(\mathrm{I})$ aryl acetylide should oxidize first the alkyl Au(I) complex and form the corresponding $\mathrm{Au}(\mathrm{III})$ alkyl acetylide. Once the $\mathrm{Au}(\mathrm{III})$ alkyl acetylide is formed, the $\mathrm{Au}(\mathrm{I})$ aryl acetylide can transmetalate. It is true that while the oxidation with selectfluor occurs, the remaining $\mathrm{Au}(\mathrm{I})$ alkyl acetylide (not oxidized yet) could compete with the $\mathrm{Au}(\mathrm{I})$ aryl acetylide to transmetalate. To avoid the self-coupling of the alkyl acetylide, we employed $\mathbf{3 b}\left(\mathrm{C}_{12}\right)$, since the rate of homocoupling is the lowest in the alkyl series and it should not compete with the aryl acetylide. Thus, the $\mathrm{Au}(\mathrm{I})$ alkyl acetylide $\mathbf{3 b}$ and $\mathrm{PPh}_{3} \mathrm{Au}$-orthotolylacetylene $3 \mathrm{c}$ were mixed in the same flask and then selectfluor was added. The result in Fig. 4d shows that the heterocoupled product $\mathbf{4 b}$ is the major product of the reaction with a $77 \%$ yield, indicating that the transmetallation from $\mathrm{Au}(\mathrm{I})$ aryl acetylides to $\mathrm{Au}(\mathrm{III})$ alkyl acetylides readily occurs.

With the hope that the digold intermediate of unreactive 1-dodecyne could be trapped and characterized, we carried out the oxidation of complex $\mathbf{6 b}$ with selectfluor at $-78^{\circ} \mathrm{C}$ in a $\mathrm{CD}_{2} \mathrm{Cl}_{2} / \mathrm{CD}_{3} \mathrm{CN}$ solvent mixture. The results (Supplementary Fig. 8) show the desymmetrization of the original $\mathrm{H}$ and $\mathrm{P}$ peaks of $\mathbf{6 b}$ into two new signals, which points to the formation of the divalent-mixed $\mathrm{Au}(\mathrm{I}, \mathrm{III})$ complex. Complex $\mathbf{6 b}$ was independently prepared without one of the dodecylide fragments and its ${ }^{31} \mathrm{P}$ NMR signal fits well with the one detected after oxidation of 6b by selectfluor, which supports that one of the dodecylide fragments of $\mathbf{6 b}$ leaves as soon as one $\mathrm{Au}(\mathrm{I})$ atom is oxidized to $\mathrm{Au}(\mathrm{III})$.

With all the above results, we can suggest that the distal size selectivity occurs just before the transmetallation step of one alkyl acetylide fragment from $\mathrm{Au}(\mathrm{I})$ to $\mathrm{Au}(\mathrm{III})$, during the formation of the mixed-valence digold (I,III) complex. The tetracoordinated planar $\mathrm{Au}(\mathrm{III})$ site and the linear $\mathrm{Au}(\mathrm{I})$ site impose a parallel disposition of the aliphatic chains of each acetylene, which resembles the formation of a highly stabilized self-assembled monolayer, in this case just via two contiguous aliphatic chains. For longer chains, their interaction is enhanced thus blocking the coupling of the alkynes, while for shorter chains the lateral interaction is weak and the reaction readily occurs.

Mechanism of gold-catalysed distal-selective alkyne coupling. Figure 5 shows the proposed mechanism to explain the origin

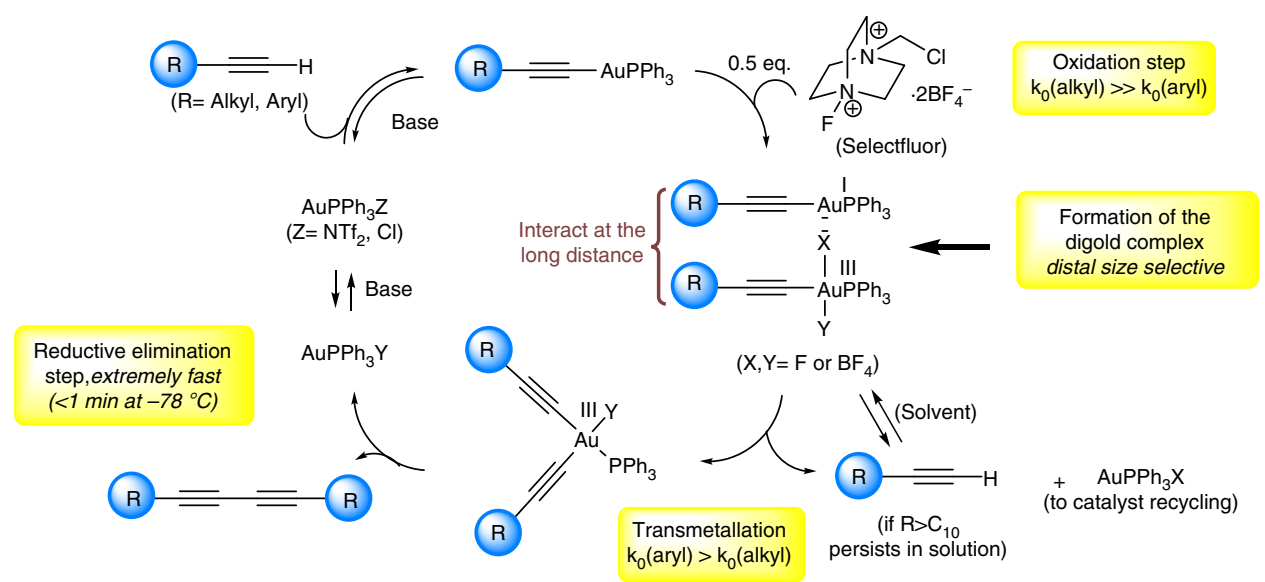

Figure 5 | Proposed mechanism for the gold-catalysed homocoupling of alkynes with distal size selectivity. The formation of a Au(I)/Au(III) digold intermediate is responsible for the distal steric differentiation. 
of size selectivity during the gold-catalysed homocoupling of alkynes.

First, the linear $\mathrm{Au}(\mathrm{I})$ acetylide complex suffers the oxidation by selectfluor to give the corresponding $\mathrm{Au}(\mathrm{III})$ complex. This oxidation is favoured by a second neighbouring $\mathrm{Au}(\mathrm{I})$ acetylide molecule in solution but no size selectivity is found for this process, since selectfluor oxidation occurs at a similar rate for both $\mathrm{C}_{10}$ and $\mathrm{C}_{12}$ gold acetylides. At this point, we propose an $\mathrm{Au}(\mathrm{I}) / \mathrm{Au}(\mathrm{III})$ intermediate with a congested structure as responsible for the distal size selectivity observed, where the tetracoordinated planar $\mathrm{Au}(\mathrm{III})$ acetylide and the dicoordinated linear $\mathrm{Au}(\mathrm{I})$ acetylide present a parallel disposition of the aliphatic chains of each acetylene, which resembles the formation of a highly stabilized self-assembled monolayer. This intermediate is supported here experimentally by the similarity of the results obtained with the digold complexes $\mathbf{5 a} \mathbf{a} \mathbf{b}$ and the corresponding acetylides of $\mathbf{5 b}$ (complexes $\mathbf{6 a - b}$ ), since these complexes have a locked cisoid conformation of acetylides and phosphines. Notice that this particular steric scenario, created by the interaction of a tetracoordinated planar metal complex and a linear metal complex, cannot be found in any metal redox pair of the periodic table but only in $\mathrm{Au}(\mathrm{I}) / \mathrm{Au}(\mathrm{III})^{40}$. In addition, this $\mathrm{Au}(\mathrm{I}) / \mathrm{Au}$ (III) intermediate suitably accommodates acetylides fully substituted in contiguous positions to the triple bond such as tertbutylacetylene 1c, which explains the feasibility of couplings with hindered alkynes around rather than along the triple bond. The experimental results also suggest that protodeauration competes with the transmetallation of the linear alkyl acetylide from $\mathrm{Au}(\mathrm{I})$ to $\mathrm{Au}(\mathrm{III})$, and that free acetylene is also released after decomposition of the fully oxidized gold acetylide. The alkyne can rebind to the $\mathrm{Au}(\mathrm{I})$ atom and enter back into the catalytic cycle provided the acetylide is still active.

Gold-catalysed heterocoupling of alkynes. The heterocoupling of terminal alkynes has been reported in the literature with different copper catalysts but, in all cases, a five-times amount of one of the alkynes must be added to achieve good yields of heterocoupling product ${ }^{47-50}$. Otherwise, with a one-to-one molar ratio of alkynes, a statistical 1:2:1 molar ratio of homo:hetero:homocoupled products, or a 1:1:1 molar ratio in some cases, is obtained ${ }^{47-50}$. In addition, the two alkynes must be differentiated either electronically (aryl or heteropropargyl versus alkyl alkynes, activated versus deactivated aryl alkynes) or sterically near the triple bond (linear versus bulky alkynes). The high excess of one of the alkyne reactants together with the need of electronic and/or steric differentiation of the terminal triple bond limits severely the application of these methodologies in organic synthesis. A much better methodology would consist in a catalytic system able to couple two different terminal alkynes regardless of the nature of the terminal triple bond and without the need of adding an excess of one of them. When we carried out the heterocoupling of different alkynes in equimolecular amounts under the present gold-catalysed conditions, we found that the heterocoupling products were formed in moderate to good yields and with high selectivity (Supplementary Fig. 9) ${ }^{51,52}$.

One must not be surprised with these results when considering the high yield of heterocoupling obtained when we mix the $\mathrm{C}_{12}$ $\mathrm{Au}(\mathrm{I})$ alkyl acetylide $\mathbf{3 b}$ and $\mathrm{PPh}_{3} \mathrm{Au}$-ortho-tolylacetylene $\mathbf{3 c}$ (see Fig. $4 \mathrm{~d}$ above). If we compare the initial rate of oxidation for the $\mathrm{Au}(\mathrm{I})$ alkyl acetylides $\left(220 \mathrm{~h}^{-1}\right.$, see above) with that of the aryl acetylide $\left(45 \mathrm{~h}^{-1}\right)^{17}$, a five-times relationship $k_{0}$ (alkyl)/ $k_{0}($ aryl $)=k_{\text {rel }}($ oxidation $) \approx 5$ is found. However, the initial reaction rate for the homocoupling of 1-decyne 1a under the gold-catalysed reaction conditions indicated above (Fig. 1) is approximately three times lower than that for ortho-tolylacetylene 1e $\quad($ ref. 17$), \quad k_{0}(\operatorname{alkyl}) / k_{0}(\operatorname{aryl})=k_{\text {rel }}($ homocoupling $)=0.36$. Therefore, the rate of oxidation of $\mathrm{Au}(\mathrm{I})$-acetylide and the rate of formation of homocoupling product are decoupled for alkyl and aryl alkynes, with an estimated value of $k_{\text {rel }}$ (oxidation)/ $k_{\text {rel }}($ homocoupling $) \approx 14$. Since the last step, the reductive elimination from $\mathrm{Au}$ (III) is extremely fast (less than a minute at $-78^{\circ} \mathrm{C}$ ) for both alkyl and aryl alkynes, the cross-coupling of aryl and alkyl terminal alkynes is favoured under the present gold-catalysed conditions. Not only that, but the cross-coupling between two different aryl alkynes and also between two different alkyl alkynes is also performed. The coupling of two different alkynes based on gold-catalysed conditions opens a reactivity window for carrying out oxidative heterocouplings of terminal alkynes in 1:1 molar ratio with yield and selectivity clearly beyond the statistical range ${ }^{53,54}$.

\section{Discussion}

A near atomically precise distal size selectivity occurs during the oxidative coupling of terminal alkynes under gold-catalysed conditions. The formation of a crowded $\mathrm{Au}(\mathrm{I}) / \mathrm{Au}(\mathrm{III})$ digold intermediate is responsible for the distal steric differentiation. Oxidation by selectfluor, transmetallation and reductive elimination do not produce distal size selectivity. The reductive elimination of two alkynes from a single $\mathrm{Au}(\mathrm{III})$ atom is extremely fast and occurs in less than a minute at $-78^{\circ} \mathrm{C}$. The subtle steric and electronic discrimination of alkynes by this goldcatalysed system allows the heterocoupling of two different alkynes in equimolecular amounts regardless of the nature of the terminal triple bond.

\section{References}

1. Leow, D., Li, G., Mei, T.-S. \& Yu, J.-Q. Activation of remote meta-C-H bonds assisted by an end-on template. Nature 486, 518-522 (2012).

2. Tang, R.-Y., Li, G. \& Yu, J.-Q. Conformation-induced remote meta-C-H activation of amines. Nature 507, 215-220 (2014).

3. Denayer, J. F. M. et al. Rotational entropy driven separation of alkane/isoalkane mixtures in zeolite cages. Angew. Chem. Int. Ed. 44, 400-403 (2005).

4. Corma, A., Rey, F., Rius, J., Sabater, M. J. \& Valencia, S. Supramolecular selfassembled molecules as organic directing agent for synthesis of zeolites. Nature 431, 287-290 (2004).

5. Cantín, A. et al. Synthesis and structure of the bidimensional zeolite ITQ-32 with small and large pores. J. Am. Chem. Soc. 127, 11560-11561 (2005).

6. Hashmi, A. S. K. Gold-catalysed organic reactions. Chem. Rev. 107, 3180-3211 (2007).

7. de Haro, T. \& Nevado, C. On gold-mediated C-H activation processes. Synthesis 16, 2530-2539 (2011).

8. Engle, K. M., Mei, T.-S., Wang, X. \& Yu, J.-Q. Bystanding F + oxidants enable selective reductive elimination from high-valent metal centers in catalysis. Angew. Chem. Int. Ed. 50, 1478-1491 (2011).

9. Zhang, L. A Non-diazo approach to $\alpha$-oxo gold carbenes via gold-catalysed alkyne oxidation. Acc. Chem. Res. 47, 877-888 (2014).

10. Boronat, M., Leyva-Pérez, A. \& Corma, A. Theoretical and experimental insights into the origin of the catalytic activity of subnanometric gold clusters: attempts to predict reactivity with clusters and nanoparticles of gold. Acc. Chem. Res. 47, 834-844 (2014).

11. Corma, A., Leyva-Pérez, A. \& Sabater, M. J. Gold-catalysed carbon-heteroatom bond-forming reactions. Chem. Rev. 111, 1657-1712 (2011).

12. Hashmi, A. S. K. Dual gold catalysis. Acc. Chem. Res. 47, 864-876 (2014).

13. Brenzovich, Jr W. E. et al. Gold-catalysed intramolecular aminoarylation of alkenes: $\mathrm{C}-\mathrm{C}$ bond formation through bimolecular reductive elimination. Angew. Chem. Int. Ed. 49, 5519-5522 (2010).

14. Tkatchouk, E. et al. Two metals are better than one in the gold catalysed oxidative heteroarylation of alkenes. J. Am. Chem. Soc. 133, 14293-14300 (2011).

15. Siemsen, P., Livingston, R. C. \& Diederich, F. Acetylenic coupling: A powerful tool in molecular construction. Angew. Chem. Int. Ed. 39, 2632-2657 (2000).

16. Stefani, H. A., Guarezemini, A. S. \& Cella, R. Homocoupling reactions of alkynes, alkenes and alkyl compounds. Tetrahedron 66, 7871-7918 (2010). 
17. Leyva-Pérez, A., Doménech, A., Al-Resayes, S. I. \& Corma, A. Gold redox catalytic cycles for the oxidative coupling of alkynes. ACS Catal. 2, 121-126 (2012).

18. Hopkinson, M. N., Ross, J. E., Giuffredi, G. T., Gee, A. D. \& Gouverneur, V. Gold-catalysed cascade cyclization-oxidative alkynylation of allenoates. Org. Lett. 12, 4904-4907 (2010).

19. Liu, L.-P., Xu, B., Mashuta, M. S. \& Hammond, G. B. Synthesis and structural characterization of stable organogold(I) compounds. Evidence for the mechanism of gold-catalysed cyclizations. J. Am. Chem. Soc. 130, 17642-17643 (2008).

20. Ball, L. T., Lloyd-Jones, G. C. \& Russell, C. A. Gold-catalysed oxidative coupling of arylsilanes and arenes: origin of selectivity and improved precatalyst. J. Am. Chem. Soc. 136, 254-264 (2014).

21. Kürti, L. \& Czakó, B. Strategic Applications of Named Reactions in Organic Synthesis 186 (Elsevier Academic Press, 2005).

22. Berners-Price, S. J. \& Sadler, P. J. Gold(I) complexes with bidentate tertiary phosphine ligands: formation of annular vs. tetrahedral chelated complexes. Inorg. Chem. 25, 3822-3827 (1986).

23. Mirabelli, C. K. et al. Antitumor activity of bis(diphenylphosphino)alkanes, their gold(I) coordination complexes, and related compounds. J. Med. Chem 30, 2181-2190 (1987)

24. Li, D., Hang, X., Che, C.-M., Lo, W.-C. \& Peng, S.-M. Luminescent gold(I) acetylide complexes. Photophysical and photoredox properties and crystal structure of $\left[\{\mathrm{Au}(\mathrm{C} \equiv \mathrm{CPh})\}_{2}\left(\mu-\mathrm{PPh}_{2} \mathrm{CH}_{2} \mathrm{CH}_{2} \mathrm{PPh}_{2}\right)\right]$. J. Chem. Soc. Dalton Trans. 19, 2929-2932 (1993).

25. Brandys, M.-C., Jennings, M. C. \& Puddephatt, R. J. Luminescent gold(I) macrocycles with diphosphine and 4,4-bipyridyl ligands. J. Chem. Soc. Dalton Trans. 24, 4601-4606 (2000).

26. Fackler, J. \& John, P. Metal-metal bond formation in the oxidative addition to dinuclear gold(I) species. Implications from dinuclear and trinuclear gold chemistry for the oxidative addition process generally. Polyhedron 16, 1-17 (1997).

27. Fackler, J. \& John, P. Forty-five years of chemical discovery including a golden quarter-century. Inorg. Chem. 41, 6959-6972 (2002).

28. Doménech, A., Leyva-Pérez, A., Al-Resayes, S. I. \& Corma, A. Electrochemical monitoring of the oxidative coupling of alkynes catalysed by triphenylphosphine gold complexes. Electrochem. Commun. 19, 145-148 (2012).

29. Cui, L., Zhang, G. \& Zhang, L. Homogeneous gold-catalysed efficient oxidative dimerization of propargylic acetates. Bioorg. Med. Chem. Lett. 19, 3884-3887 (2009).

30. Zhang, G., Peng, Y., Cui, L. \& Zhang, L. Gold-catalysed homogeneous oxidative cross-coupling reactions. Angew. Chem. Int. Ed. 48, 3112-3115 (2009).

31. Hopkinson, M. N. et al. Gold-catalysed intramolecular oxidative cross-coupling of nonactivated arenes. Chem. Eur. J. 16, 4739-4743 (2010).

32. Zhang, G., Cui, L., Wang, Y. \& Zhang, L. Homogeneous gold-catalysed oxidative carboheterofunctionalization of alkenes. J. Am. Chem. Soc. 132, 1474-1475 (2010).

33. Wolf, W. J., Winston, M. S. \& Toste, F. D. Exceptionally fast carbon-carbon bond reductive elimination from gold(III). Nat. Chem. 6, 159-164 (2014).

34. Hashmi, A. S. K. Homogeneous gold catalysis beyond assumptions and proposals-characterized intermediates. Angew. Chem. Int. Ed. 49, 5232-5241 (2010).

35. Hofer, M. \& Nevado, C. Unexpected outcomes of the oxidation of (pentafluorophenyl)triphenylphosphanegold(I). Eur. J. Inorg. Chem. 9, 1338-1341 (2012)

36. Hashmi, A. S. K. et al. Dual gold catalysis: $\sigma, \pi$-propyne acetylide and hydroxylbridged digold complexes as easy-to-prepare and easy-to-handle precatalysts. Chemistry 19, 1058-1065 (2013).

37. Méndez, L. A., Jiménez, J., Cerrada, E., Mohr, F. \& Laguna, M. A Family of alkynylgold(III) complexes $\left[\mathrm{Au}^{\mathrm{I}}\left(\mu-\left\{\mathrm{CH}_{2}\right\}_{2} \mathrm{PPh}_{2}\right)_{2} \mathrm{Au}^{\mathrm{III}}(\mathrm{C} \equiv \mathrm{CR})_{2}\right](\mathrm{R}=\mathrm{Ph}, \mathrm{tBu}$, $\mathrm{Me}_{3} \mathrm{Si}$ ): facile and reversible comproportionation of gold(I)/gold(III) to digold(II). J. Am. Chem. Soc. 127, 852-853 (2005).

38. Au, V. K.-M., Wong, K. M.-C., Zhu, N. \& Yam, V. W.-W. Luminescent cyclometalated dialkynylgold(III) complexes of 2-phenylpyridine-type derivatives with readily tunable emission properties. Chem. Eur. J. 17, 130-142 (2011).
39. Schwerdtfeger, P. Relativistic effects in gold chemistry. 2 . The stability of complex halides of gold(III). J. Am. Chem. Soc. 111, 7261-7262 (1989).

40. Gorin, D. J. \& Toste, F. D. Relativistic effects in homogeneous gold catalysis. Nature 446, 395-403 (2007).

41. Leyva-Pérez, A. \& Corma, A. Similarities and differences between Gold, Platinum and Mercury "relativistic" triad in catalysis. Angew. Chem. Int. Ed. 51, 614-635 (2011).

42. Leyva, A., Zhang, X. \& Corma, A. Chemoselective hydroboration of alkynes vs. alkenes over gold catalysts. Chem. Commun. 33, 4897-5044 (2009).

43. Usón, R., Laguna, A. \& Vicente, J. Novel anionic gold(I) and gold(III) organocomplexes. J. Organomet. Chem. 131, 471-475 (1977).

44. Khairul, W. M. et al. Transition metal alkynyl complexes by transmetallation from $\mathrm{Au}(\mathrm{C} \equiv \mathrm{CAr})\left(\mathrm{PPh}_{3}\right)\left(\mathrm{Ar}=\mathrm{C}_{6} \mathrm{H}_{5}\right.$ or $\left.\mathrm{C}_{6} \mathrm{H}_{4} \mathrm{Me}-{ }_{4}\right)$. Dalton Trans. 4, 610-620 (2009).

45. Chen, Y., Chen, M. \& Liu, Y. Gold-catalysed cyclization of 1,6-diyne-4-en-3-ols: stannyl transfer from 2-tributylstannylfuran through $\mathrm{Au} / \mathrm{Sn}$ transmetallation. Angew. Chem. Int. Ed. 51, 6181-6186 (2012).

46. Hofer, M., Gomez-Bengoa, E. \& Nevado, C. A Neutral gold(III) - boron transmetallation. Organometallics 33, 1328-1332 (2014).

47. Yin, W., He, C., Chen, M., Zhang, H. \& Lei, A. Nickel-catalysed oxidative coupling reactions of two different terminal alkynes using $\mathrm{O}_{2}$ as the oxidant at room temperature: facile syntheses of unsymmetric 1,3-diynes. Org. Lett. 11, 709-712 (2009).

48. Balaraman, K. \& Kesavan, V. Efficient copper(II) acetate catalysed homo and heterocoupling of terminal alkynes at ambient conditions. Synthesis 20, 3461-3466 (2010).

49. Xiao, R., Yao, R. \& Cai, M. Practical oxidative homo- and heterocoupling of terminal alkynes catalysed by immobilized copper in MCM-41. Eur. J. Org. Chem. 22, 4178-4184 (2012).

50. Navale, B. S. \& Bhat, R. G. Copper(I) iodide-DMAP catalysed homo- and heterocoupling of terminal alkynes. RSC Adv. 3, 5220-5226 (2013).

51. Ohashi, K. et al. Indonesian medicinal plants. XXV.1) Cancer cell invasion inhibitory effects of chemical constituents in the parasitic plant scurrula atropurpurea (Loranthaceae). Chem. Pharm. Bull. 51, 343-345 (2003).

52. Xu, Z., Byun, H.-S. \& Bittman, R. Synthesis of photopolymerizable long-chain conjugated diacetylenic acids and alcohols from butadiyne synthons. J. Org. Chem. 56, 7183-7186 (1991).

53. Lee, S., Lee, T., Lee, Y. M., Kim, D. \& Kim, S. Solid-phase library synthesis of polyynes similar to natural products. Angew. Chem. Int. Ed. 46, 8422-8425 (2007).

54. Liu, J., Lam, J. W. Y. \& Tang, B. Z. Acetylenic polymers: syntheses, structures, and functions. Chem. Rev. 109, 5799-5867 (2009).

\section{Acknowledgements}

Financial support by Consolider-Ingenio 2010 (proyecto MULTICAT) and Severo Ochoa programs from MCIINN and Prometeo program from Generalitat Valenciana is acknowledged. A. L.-P. thanks ITQ for the concession of a contract. We thank Dr J.A. Vidal for assistance with the low-temperature NMR experiments, and Dr M. Boronat for the DFT calculations.

\section{Author contributions}

A.L.-P. carried out the experiments and wrote the manuscript. A.D.-C. carried out the electrochemistry and wrote the conclusions thereof. A.C. wrote the manuscript.

\section{Additional information}

Supplementary Information accompanies this paper at http://www.nature.com/ naturecommunications

Competing financial interests: The authors declare no competing financial interests.

Reprints and permission information is available online at http://npg.nature.com/ reprintsandpermissions/

How to cite this article: Leyva-Pérez, A. et al. Unique distal size selectivity with a digold catalyst during alkyne homocoupling. Nat. Commun. 6:6703 doi: 10.1038/ncomms7703 (2015). 